\title{
Analisis Pengaruh Variasi Arus terhadap Kualitas Sambungan Hasil Pengelasan GTAW pada Material SA 266 Gr 2N with Clad Inconel 625 (Tube Sheet) dengan SA 213 TP 304 (Tube)
}

\author{
Praditya Hadi Prabowo, Rochman Rochiem dan Wikan Jatimurti \\ Departemen Teknik Material dan Metalurgi, Fakultas Teknologi Industri, Institut Teknologi Sepuluh Nopember
}

(ITS)

\begin{abstract}
Abstrak-HP Heater adalah sebuah peralatan Heat Exchanger yang terdiri dari Shell \& Tube yang digunakan untuk menaikkan temperatur feed water sesuai temperatur yang dipersyaratkan oleh Boiler.Material yang cocok digunakan SA 213 TP 304 dan Inconel 625 dipilih Karena yang memiliki ketahanan korosi yang baik. Sifat ketahanan korosi,ketahanan terhadap panas dan tekanan material muncul Karena adanya nickel dan chrom. Kedua material ini dilas menggunakan metode GTAW (Gas Tungstan Arc Welding),akan tetapi sering di jumpai di lapangan terjadi kebocoran pada material ini.. Tujuan dari penelitian ini adalah untuk menganalisis pengaruh heat input (arus) terhadap sifat mekanik dan struktur mikro pada hasil pengelasan SA 266 GR2N Inconel 625 dengan SA 213 TP 304. Pada penelitian ini material dilas menggunakan GTAW. Proses pengelasan yang dilakukan menggunakan variasi heat input dengan arus 65A,70A,75A,80A,85A, Pengujian yang dilakukan pada penelitian kali ini adalah uji makro, uji mikro, uji XRD, uji kekerasan. Dari pengujian tersebut didapatkan bahwa parameter aman untuk dilakukan pengelasan pada arus 65A dan 70A.Ditemukan persipitat karbida pada parameter 75A dan $80 \mathrm{~A}$.
\end{abstract}

Kata Kunci-SA 213 TP 304, Clad Inconel 625, GTAW, arus, kecepatan pengelasan, struktur mikro, kekerasan.

\section{PENDAHULUAN}

$\mathrm{H}$ P Heater adalah sebuah peralatan Heat Exchanger yang terdiri dari Shell \& Tube yang digunakan untuk menaikkan temperatur feed water sesuai temperatur yang dipersyaratkan oleh Boiler. Siklus tertutup adalah steam (uap) yang dihasilkan oleh Boiler digunakan oleh steam turbin untuk menggerakkan generator dikondensasi menjadi air condensate untuk digunakan kembali menjadi steam. Proses tersebut dilakukan oleh Condenser, Gland Condenser, LP Heater, Deaerator, Boiler Feed Pump dan HP Heater Steam (uap) yang telah digunakan oleh steam turbin sebagian dikeluarkan kepada HP Heater digunakan memanaskan feed water yang masuk melalui Tube. Uap yang mempunyai temperatur tinggi dialirkan ke dalam Shell dan memanaskan bagian luar permukaan Tube sedangkan feed water dialirkan di dalam Tube. Bagian penting HP Heater yaitu Water chamber (sisi Tube) terdiri dari Inlet dan outlet feed water. Sisi Sheel terdiri dari shell dan tube,karena HP Heater bekerja pada tekanan dan temperatur yang tinggi. Salah satu komponen pada $H P$ Heater yang sering mengalami kegagalan atau kerusakan yaitu retak pada daerah las antara tube dan tubesheet. Kerusakan tersebut disebabkan oleh tekanan tinggi dari feedwater pada tube. GTAW (Gas Tungsten Arc Welding) merupakan jenis las listrik yang menggunakan elektroda tidak terkonsumsi. Elektroda yang digunakan pada metode ini hanya untuk menghasilkan busur listrik. Metode ini menggungakan bahan tambahan berupa filler (rod) untuk mencegah oksidasi menggunakan gas mulia (seperti Argon, Helium, Ferron) dan karbon dioksida sebagai gas lindung. Dalam proses pengelasan, ada beberapa yang perlu diperhatikam, seperti heat input (meliputi ampere, voltase, dan kecepatan pengelasan), elektroda yang digunakan, serta gas pelindung yang digunakan. Parameter-parameter di atas dapat berubahubah nilainya tergantung dari material yang digunakan. Pemilihan heat input yang benar akan menghindari cacat las yang terjadi. Perubahan heat input dapat berpengaruh pada lebar HAZ. Sifat mekanik dan struktur mikro juga dapat berubah akibat perubahan parameter. Selain parameter pengelasan, unsur paduan yang terdapat pada material dan kecepatan pendinginan juga dapat mempengaruhi struktur mikro dan sifat mekanik.Di PT. PAL Indonesia sendiri SA 266 GR2N Inconel 625(tube sheet) dengan SA 213 TP 304 (tube) ini digunakan untuk komponen yang mengalirkan fluida pada HP heater. Penelitian ini dilakukan untuk mengetahui pengaruh variasi heat input terhadap sifat mekanik dan struktur mikro pada pengelasan SA 266 GR2N Inconel 625(tube sheet) dengan SA 213 TP 304 (tube) dengan metode GTAW dengan pendinginan secara cepat

\section{II.METODE PENELITIAN}

\section{A. Bahan yang digunakan}

Bahan yang digunakan pada penelitian ini antara lain, SA 266 GR2N (tube sheet), 2. SA 213 TP 304 (tube), Elektroda ERNiCrMo-3.

\section{B. Pengamatan Makroskopik}

Pengamatan makro dilakukan untuk mengetahui bentuk dan tampilan dari permukaan spesimen dan lebar HAZ setelah dilakukan pengelasan. Pengamatan makro dilakukan menggunakan kamera. perhitungan. 


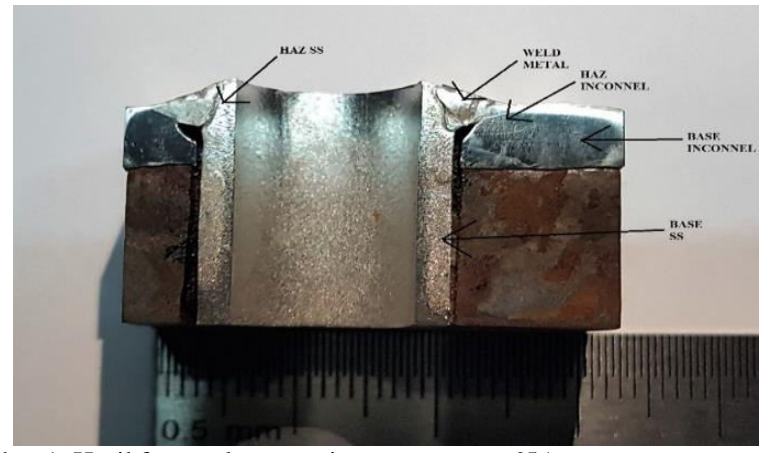

Gambar 1. Hasil foto makro sepesimen parameter 65A.

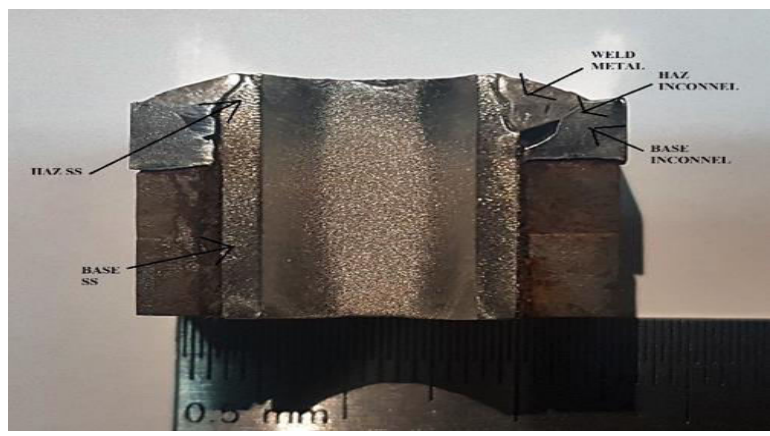

Gambar 2. Hasil foto makro sepesimen parameter 70A.

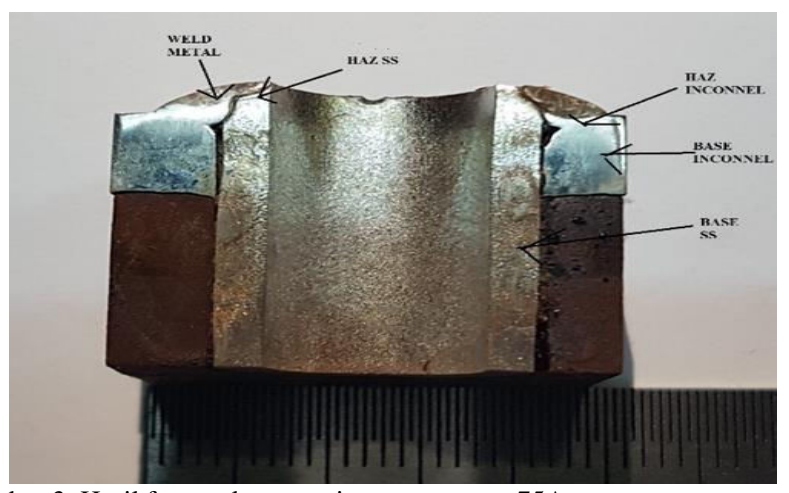

Gambar 3. Hasil foto makro sepesimen parameter 75A.

Lebar HAZ dapat ditentukan dengan formula di bawah ini:

$$
\begin{aligned}
& H_{\text {nett }}=\frac{\eta \cdot E \cdot I}{V} \\
& \frac{1}{T_{p}-T_{o}}=\frac{4.13 \rho C t Y}{H_{\text {net }}}+\frac{1}{T_{m}-T_{o}}
\end{aligned}
$$

Dimana:

$\mathrm{H}_{\text {nett }}=$ Heat Input $(\mathrm{HI})(\mathrm{J} / \mathrm{mm})$

$\mathrm{E} \quad=$ Tegangan $($ Volt $) \mathrm{I}=$ Arus (Ampere)

$\mathrm{V}=$ Kecepatan pengelasan $(\mathrm{mm} / \mathrm{s})$

$\eta \quad=$ efisiensi pengelasan $(\mathrm{GTAW}=0.6)$

$\rho \mathrm{C}=0.5 \mathrm{~J} / \mathrm{mm} 3 . \mathrm{oC}$

$\mathrm{t}=$ Kecepatan las

To $\quad=$ Temperetur Awal

$\mathrm{Tm} \quad=$ Temperatur Leleh

$\mathrm{Tp} \quad=$ Temperatur Puncak

\section{Pengamatan Mikroskopik}

Pada pengamatan mikroskopik dengan mikroskop optik dilakukan untuk menganalisis fasa, bentuk, dan ukuran

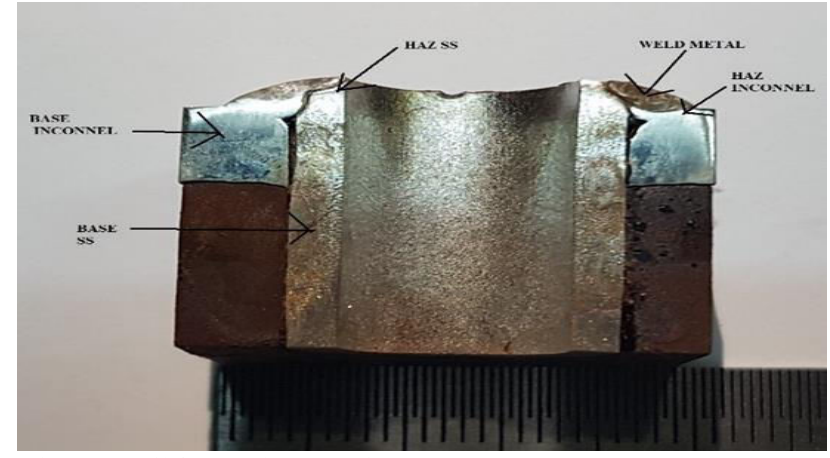

Gambar 4. Hasil foto makro sepesimen parameter 80A.

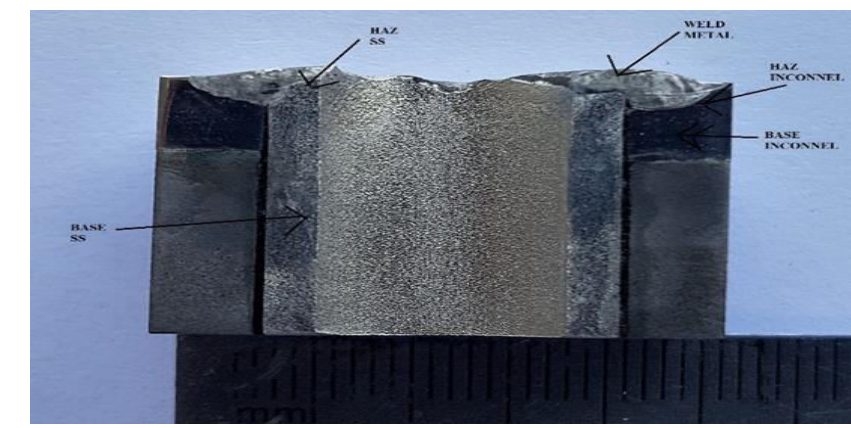

Gambar 5. Hasil foto makro sepesimen parameter 85A.

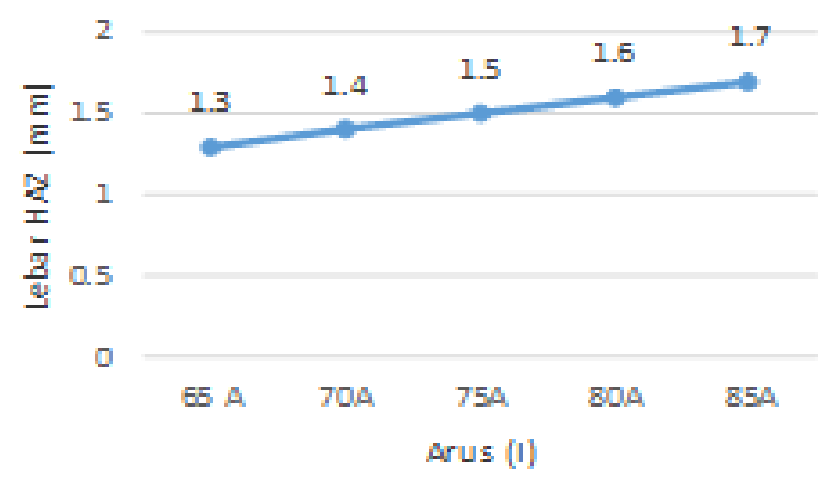

Gambar 6. Lebar HAZ.

strukturmikro. Pengujian ini dilakukan dengan menggunakan mikroskop optik Olympus BX51M-RF.

\section{Uji Senyawa}

Uji senyawa dengan sistem karakterisasi oleh difraksi Sinar-X (XRD) yang dilakukan menggunakan alat Pan Analitycal XRD di Laboratorium Karakterisasi Teknik Material dan Metalurgi. Karakterisasi ini dilakukan untuk melihat struktur kristal dan fase-fase yang terbentuk.

\section{E. Uji Kekerasan}

Pengujian kekerasan dilakukan untuk mengetahui distribusi nilai kekerasan pada spesimen menggunakan metode Vickers Hardness Test dengan beban $10 \mathrm{kgf}$ berdasarkan ASTM E-92. Terdapat 5 daerah yang dilakukan indentasi yaitu base metal SS, HAZ SS, Weld Metal, HAZ Inconel dan base metal Inconel 625 Pengujian ini menggunakan indentasi sebanyak 3 titik di setiap daerahnya. 


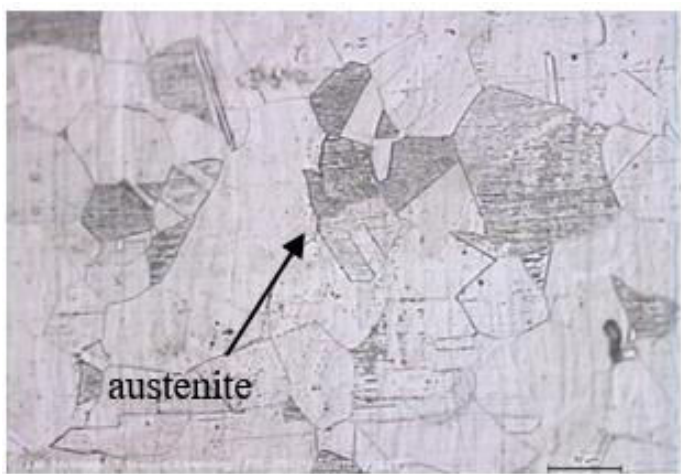

Gambar 7. Pengamatan mikroskopik pada daerah Base Metal.

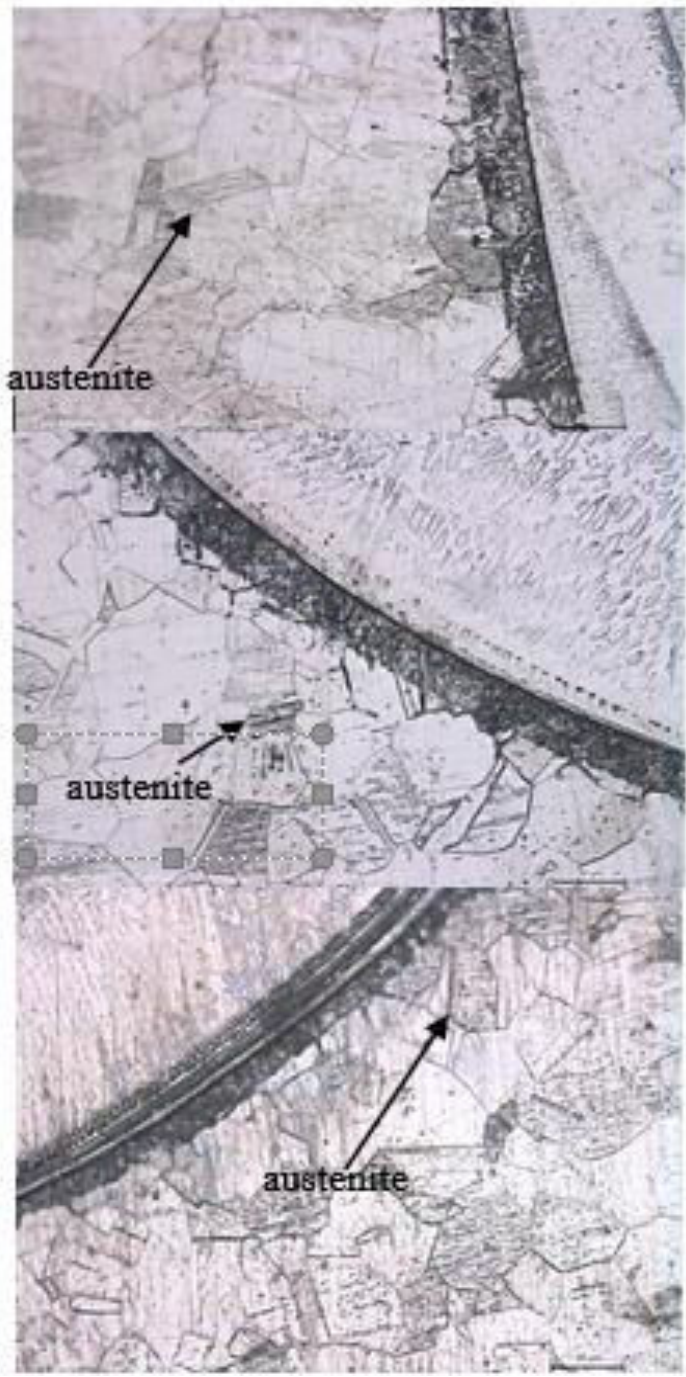

Gambar 8. Pengamatan mikroskopik pada daerah HAZ pada parameter 65A,70A dan 85A.

\section{HASIL DAN PEMBAHASAN}

\section{A. Pengamatan Makroskopik}

Pengamatan secara makro ini dilakukan dengan etsa glycergia. Pada gambar 1 hingga 5 hanya terlihat batas antara weld metal dan base metal, pada gambar 5 weld metal menunjukan adanya pengurangan dimensi pada permukaan pipa.

Bentuk dan lebar HAZ pada umumnya dipengaruhi oleh besarnya heat input yang diberikan dan kecepatan

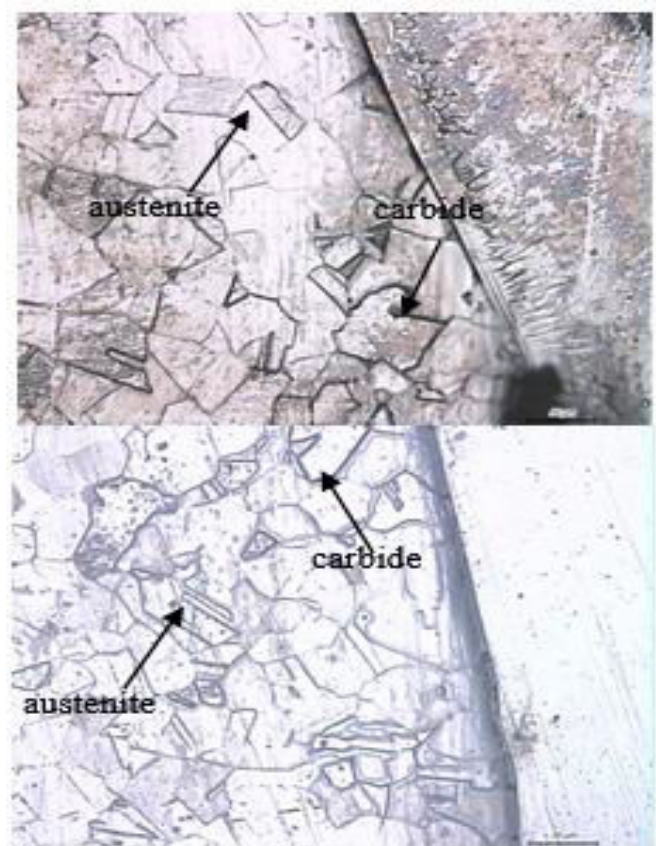

Gambar 9. Pengamatan mikroskopik pada daerah HAZ pada parameter $75 \mathrm{~A}$ dan $80 \mathrm{~A}$.

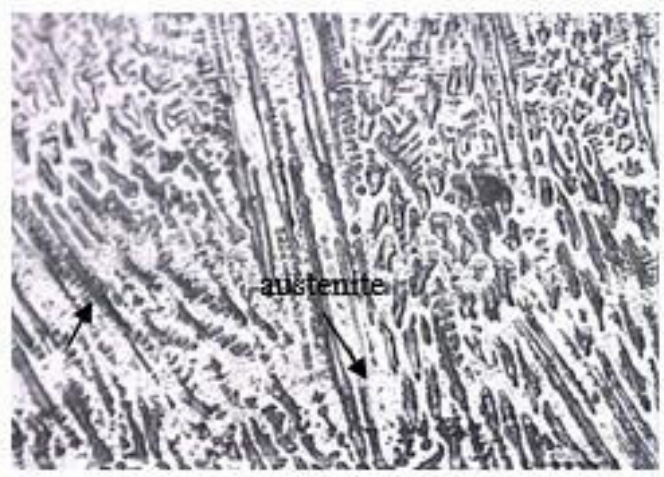

Gambar 10. Pengamatan mikroskopik pada permukaan daerah Weld Metal.

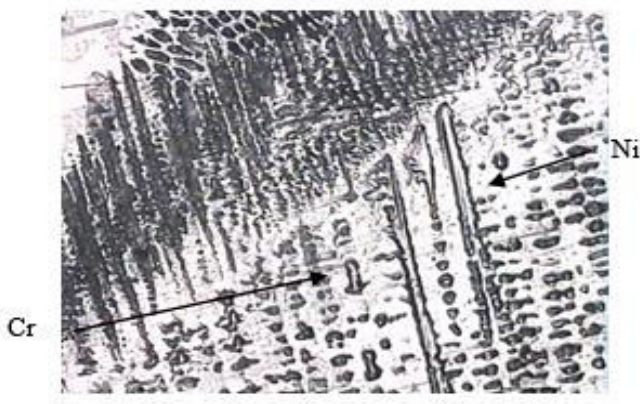

Gambar 11. Pengamatan mikroskopik pada permukaan daerah Inconel 625.

pengelasan.didapatkan hasil perhitungan lebar HAZ adalah didapatkan semakin tingginya heat input yang diberikan, lebar HAZ semakin membesar. Hal ini disebabkan semakin tinggi masukan panas, menyebabkan daerah HAZ semakin melebar. 

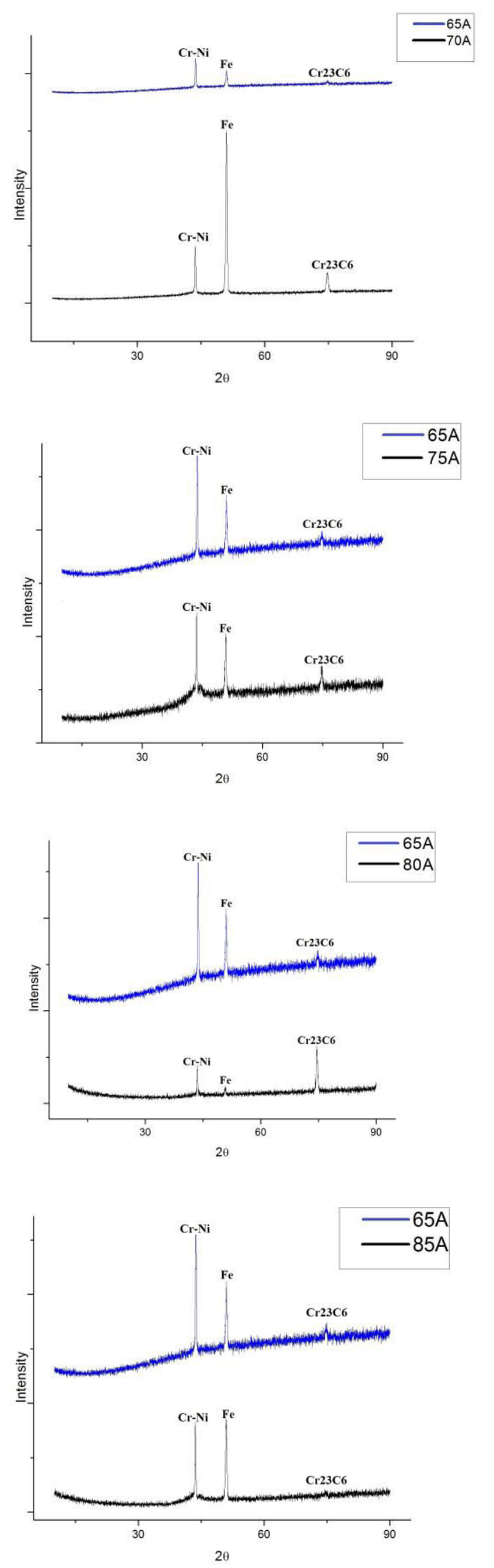

Gambar 12. Hasil XRD pada daerah HAZ Stainles steel 213 TP 304.

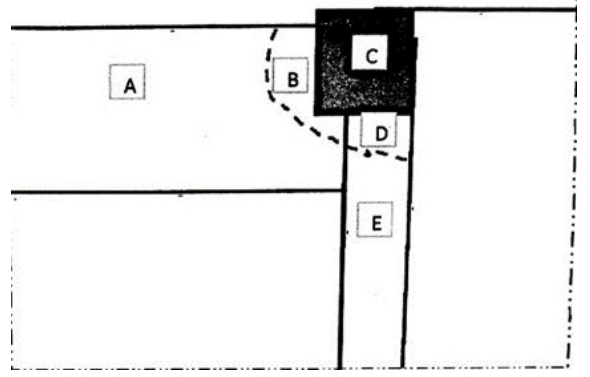

Gambar 13. Daerah indentasi pengujian kekerasan pada spesimen las.

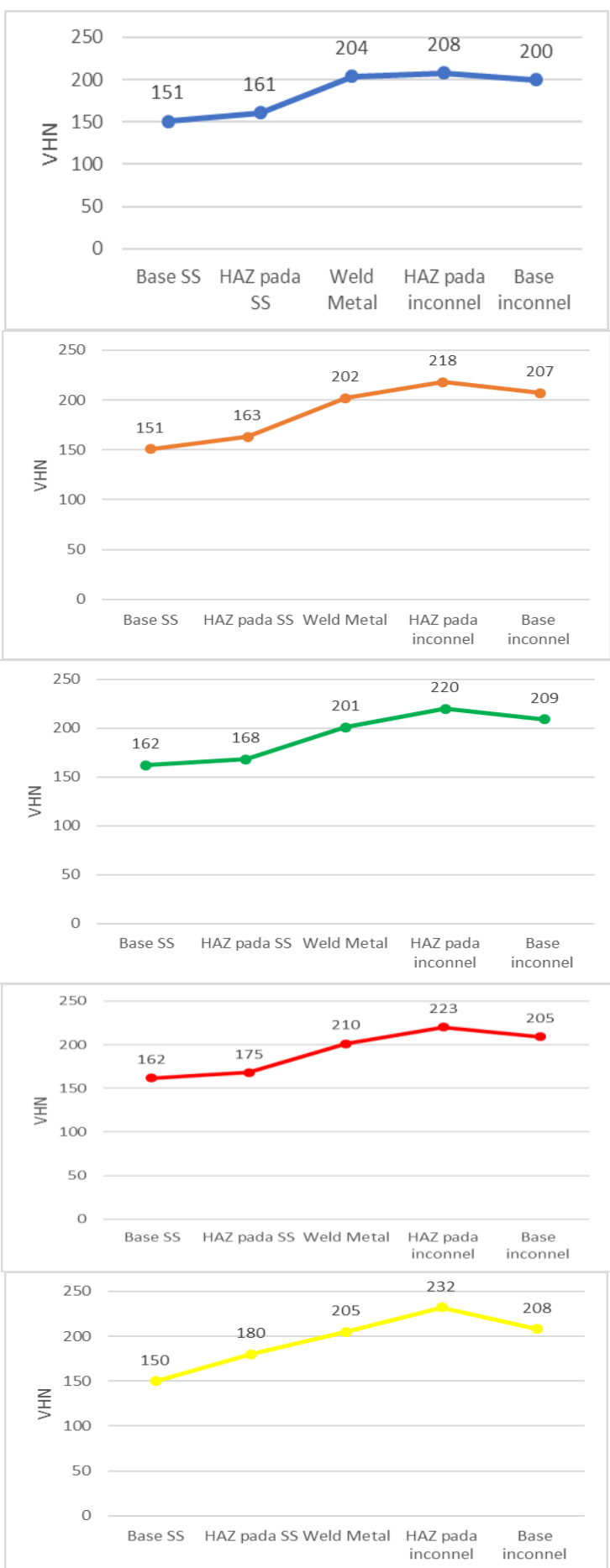

Gambar 14. Grafik persebaran nilai kekerasan pada spesimen las. 


\section{B. Pengamatan Mikroskopik}

Dari hasil struktur mikro, didapatkan perbedaan struktur di antara daerah base metal, HAZ, dan weld metal. Pada daerah HAZ ukuran butir yang terbentuk lebih halus daripada daerah base metal. Hal ini dikarenakan daerah HAZ mendapatkan panas yang lebih tinggi dari pemberian heat input daripada daerah base metal.Pada base metal material SA 213 TP 304 parameter $65 \mathrm{~A}, 70 \mathrm{~A}$ dan $85 \mathrm{~A}$ menunjukan daerah austenite yang lebih luas.

Gambar 9 pada parameter $75 \mathrm{~A}$ dan $80 \mathrm{~A}$ terbentuk persipitat karbida yang ditunjukan dengan adanya penyempitan daerah austenite dan grain boundary yang menujukan penebalan, karena adanya penurunan kadar krom (cromium depelted zone) yang pada daerah dekat batas butir [1], Pada saat pengelasan pada parameter $75 \mathrm{~A}$ dan $80 \mathrm{~A}$ panas masuk (heat input) dalam daerah sensisitas untuk stainless steel sehingga terbentuk presipitat karbida

Pada weld metal didapatkan hasil struktur mikro eutectic ferrite ini terjadi karena adanya pembentukan delta ferrite pada daerah weld metal, perubahan dari logam cair menjadi padat pada weld metal ini mengakibatkan strukturmikro dendritik pada daerah weld metal. Austenitik terbentuk melalui reaksi peritektik-eutektik dan terdapat pada batas solidifikasi akhir delta ferit di akhir solidifikasi. Pada akhir solidifikasi delta ferit, reaksi peritektik-eutektik membentuk austenit sepanjang sel ferit dan batas dendrit. Ketika pendinginan selesai, struktur mikro teridiri dari dendrit feritik dan layer interdendritik austenit. Banyaknya austenit yang terbentuk tergantung pada kondisi pendinginan. Pembekuan weld metal melalui dua fasa ferit-austenit, ferit menjadi tidak stabil dan austenit mereduksi ferit melalui reaksi difusi [2] Pada daerah HAZ Inconel dan base metal Inconel didapatkan hasil struktur mikro eutectic lamellar dengan butir dengan kandungan dominan $\mathrm{Ni}$ yang ditunjukan dengan warna lebih cerah dan $\mathrm{Cr}$ yang memiliki warna lebih gelap

\section{Uji Senyawa}

Pada hasil pengujian senyawa pada parameter $65 \mathrm{~A}$ dan $85 \mathrm{~A}$ menggunakan XRD pada weld metal $\mathrm{Fe}$ dan $\mathrm{Cr}-\mathrm{Ni}$, didapatkan hasil bahwa tidak ditemukan senyawa yang mengindikasikan adanya persipitat karbida,akan tetapi pada daerah HAZ Stainless steel dengan parameter 75 dan 80A ditemukan senyawa $\mathrm{Cr}_{23} \mathrm{C}_{6}$ (persipitat karbida)Presipitasi karbida terbentuk.ditunjukan dengan adanya penebalan batas butir (chromium depleted zone) yang ditunjukan pada gambar 9.

\section{Uji Kekerasan}

Gambar 13 menunjukkan daerah indentasi uji kekerasan pada spesimen las. Gambar 14 memperlihatkan kenaikan nilai kekerasan dari daerah Base SS, HAZ SS, Weld Metal,HAZ Inconel dan Base Inconel. Pada hasil pengujian kekerasan, didapatkan hasil bahwa daerah base metal memiliki nilai kekerasan yang rendah dibandingkan daerah weld metal. Nilai kekerasan pada weld metal tinggi dikarenakan oleh proses peleburan dari 3 material yang memiliki kekerasan yang berbeda(Inconel 625,SS 304,ERNiCrMo-3), perambatan panas yang mengakibatkan adanya perubahan pada batas butir(grain boundary) dan Sedangkan pada daerah HAZ memiliki nilai kekerasan yang lebih tinggi dari base metal. hal ini disebasbkan oleh ukuran butir austenit yang lebih halus pada HAZ daripada daerah base metal. Dan semakin bertambahnya heat input, nilai kekerasannya semakin bertambah [3]. Berdasarkan gambar 11 Material Inconnel 625 memiliki kekerasan yang lebih tinggi dari baja SS 304 .

\section{PEMBAHASAN}

Berdasarkan hasil pengujian yang telah dilakukan, faktorfaktor penyebab kegagalan dapat disederhanakan menjadi 2 aspek yaitu pengaruh Heat Input dan kekerasan material. Dari aspek Heat Input, dapat diketahui bahwa adanya $\mathrm{Cr}_{23} \mathrm{C}_{6}$ pada temperature $600^{\circ} \mathrm{C}-800^{\circ} \mathrm{C}$ mengakibatkan penurunan kadar crome karena crome diikat oleh carbon yang mengakibatkan terjadi penebalan batas butir dimana carbide mengendap di batas butir Selanjutnya, aspek kekerasan, daerah base metal memiliki nilai kekerasan yang rendah dibandingkan daerah weld metal. Nilai kekerasan pada weld metal tinggi dikarenakan oleh proses peleburan dari 3 material yang memiliki kekerasan yang berbeda (Inconel 625,SS 304,ERNiCrMo-3),perambatan panas yang mengakibatkan adanya perubahan pada batas butir(grain boundary) dan Sedangkan pada daerah HAZ memiliki nilai kekerasan yang lebih tinggi dari base metal. hal ini disebasbkan oleh ukuran butir austenit yang lebih halus pada HAZ daripada daerah base metal. Dan semakin bertambahnya heat input, nilai kekerasannya semakin bertambah.

\section{V.KESIMPULAN/RINGKASAN}

Berdasarkan hasil penelitian yang didapatkan, dapat ditarik kesimpulan sebagai berikut:

1. Hasil dari proses pengelasan didapatkan parameter optimal adalah 65A dan 70A yang dapat ditinjau dari struktur mikro yang tidak terdapat cacat

2. Ditemukan persipitat karbida pada parameter $75 \mathrm{~A}$ dan 80 . Munculnya persipitat karbida ini disebabkan oleh terikatnya $\mathrm{Cr}$ dengan $\mathrm{C}$ membentuk persipitat karbida yang mengendap di batas butir,ditunjukan dengan adanya penebalan batas butir.

3. Hasil kekerasan pada Inconel 625 lebih tinggi dibandingkan dengan stainless steel 304. Hal ini disebabkan oleh kadar nickel Inconel 625 yang lebih tinggi dari stainless steel 304.

\section{DAFTAR PUSTAKA}

[1] A. Koscieova, "Study Of The Sensitazion On The Grain Boundary In Austenitc Stainless Steel AISI 316," Bratislava, 2014.

[2] A. F. Sunandar, "Perbedaan Karakteristik Hasil Pengelasan GTAW dan SMAW Terhadap Baja Tahan Karat 316 L,” Jakarta, 2012.

[3] M. I. Khan, Welding Science and Technology. Lucknow: New Age International Publisher, 2007. 